\title{
Critical collaborations
}

\section{An information literacy across the curriculum project}

$\mathbf{T}$

wenty-first century students on the path to becoming lifelong learners through the acquisition and internalization of information literacy skills should then become thinkers. The ability to use academic library resources critically is increasingly essential for student success, as students navigate through both college and life.

These skills can best be taught through a collaborative process and librarians and teaching faculty working together provide the ideal combination. Expanding information literacy across the curriculum is one way to achieve this goal. We were delighted to receive funding from our college to support a project to investigate what happens when four classroom assignments from different disciplines are integrated with several critical thinking skills.

The title of our grant was "Collaboration and Information: Critical Thinking Skills Across the Curriculum." The goal of our project was that our students should come to understand what information is, the type of information they need and how to evaluate the appropriateness of that information, and further to apply research skills using critical thinking.

Queensborough Community College was founded in 1969 as one of the campuses of the City University of New York. Queensborough currently serves a multicultural population of approximately 15,000 students from some 143 countries, and more than 46 percent speak a language other than English at home. Community colleges serve a distinct population. Seventy-five percent of our students enter at a remedial level. For those students, it is essential to learn skills and obtain college credits at the same time.

According to the literature, there is evidence that added exposure to instruction on how to do research increases students' comfort level and therefore usage.

In a study done with undergraduates in 2006 to determine the relationship between critical thinking skills and library anxiety, "students . . . reported . . . that their critical thinking skills improved as they gained more experience with the library research process.

" This, then, extended to their comfort level, which is an essential piece of students ability to research successfully. Therefore, as a result of information literacy classes, students should begin to build on the knowledge they gain and become lifelong learners with the confidence and skills to locate and use information appropriately.

As the information literate individual becomes a critical thinker, more than simply knowing how to find information, he or she learns to build a bridge between information and where and how it needs to be applied. Students need to be able to evaluate what they find during the research process and come to conclusions. This is where the interconnectedness between critical thinking and information literacy occurs. Or as

Devin McKay is deputy chief librarian/faculty outreach, e-mail:dmckay@qcc.cuny.edu, and Sheila Beck, e-mail: sbeck@qcc.cuny.edu, is acquisitions and coordinator of technical services at Queensborough Community College

(0) 2011 Devin McKay and Sheila Beck 
Nahyun Kwon of the University of South Florida states in her article entitled "Critical Thinking and Library Anxiety among Undergraduate Students": "Students need to become aware that information seeking often involves critical thinking in identifying and evaluating relevant resources from a myriad of information sources and databases." 2

\section{Research project}

When we began our project, our main research question was: To what extent will students critical thinking abilities improve following a library research skills intervention? We worked with four sections of nursing classes, two sections of an English 101 class, a general music class, and one criminal justice class. We used pretests and post tests to measure the students' information literacy and critical thinking skills. For our model, we chose three competencies based on work done in 1994 by the Information Competence Work Group of the California State University (CSU). ${ }^{3}$

In keeping with the Middle States focus on Gen Ed, these competencies expand on Gen Ed objective five-integrating knowledge and skills into students' program of study. Each of the subject areas had different scenarios that were relevant to their assignment. The following are the scenarios for the criminal justice students.

The first scenario addresses competency one: "Formulate and state a research question, problem or issue." You are working in a group to study criminal theory in its historical context. Your task is to inform the American Criminal Justice Association on this criminal theory. What type of information do you need to know? How would you use this information to describe criminal theory and its historical context?

The second scenario addresses competency two: "Determine the information requirements for a research question, problem or issue in order to formulate a search strategy that will use a variety of resources." In the question-and-answer period, an audience member asks what is the theory's current usage and its application to a well-known criminal. What type of information do you want to know? How would you evaluate the information you find?

The third scenario addresses competency three: "Locate and retrieve relevant information, in all its various formats, using when appropriate, technological tools." You need to know everything about Charles Manson. You will need to find information on his life and crimes. How would you locate the information? What type of information would you expect to find?

The pretest and the post tests used the same scenarios to see how the students responses would differ after the library lesson. The following are examples of how the students answered in the pre- and post test. One pretest answer for scenario one was, "You find the information depending on what matter you want to talk about." One post test answer for the same scenario was, "I would need a primary document/source by the theorist."

For scenario two, a pretest answer was, "I need to find if my theory is still in practice with Google," and one post test answer was, "I would evaluate by researching who and what and where the theory originated."

For scenario three, one pretest answer was, "Google, lots of miscellaneous items ranging from what I need to nonsense" and a post-test answer was, "Information would be located on the school's databases in order to obtain correct information." The post test answers generally showed that the students learned something about the library's resources and how to use them.

The guidelines for scoring the answers to the scenarios have also been obtained from CSU.

\section{Project results}

The responses to the pre- and post tests were evaluated by the breadth and depth of student answers. We chose to evaluate the breadth of the responses by using the number of sentences or phrases. Responses are also quantified by depth, which we defined 
as the number of discrete concepts given to elaborate on the specific idea described in the sentence or phrase. We coded the answers of the pre- and post tests and compared the scores.

The following is an example from a pretest from that we scored as 1 for breadth. This came from the first scenario used for the assignment in the nursing department. "First of all, I have to have a basic idea about nutrition." The score of 1 comes from the "basic idea about nutrition." The "basic idea about nutrition" is also scored as one depth.

For the pretest, we found when we added the scores of breadth and the scores of depth in each subject area that the beginning students had lower scores than the more advanced. The music students who had some library instruction in other classes scored higher than those who did not and they mentioned specific library resources. This was also true of the criminal justice class. But those classes overall had the lowest depth and breadth in their answers in the pretest. The English classes had the next highest scores in breadth and depth, and the nursing classes had the highest. ${ }^{4}$

The CSU study showed that the greater the breadth and depth of responses to the scenarios, the greater the research process skills. I think we would have found that as well, but the timing of the post test made the difference. We gave the post tests at the end of the semester when the students were stressed and tired, and this showed in their answers. When we got the post tests, back the results were disappointing. The students were burnt out at and did not give expansive answers. ${ }^{5}$

\section{Analysis}

Across the board, the breadth and depth was lower, but, interestingly, the qualities of the answers were better and more focused. Many of the students responded with an appropriate source or said they would come to the library to do research. Of the sources used the increase in library resources from the pretest to the post test was encouraging. The criminal justice students needed to find primary documents and many of their answers indicated that they understood what that meant and where to find it. They needed to find biographical information and they knew where to go for that, as well.

We also evaluated the number and types of sources that the students said they would use to answer the questions. In the pretest, while all the students mentioned online as a resource, again the nursing students scored the highest by choosing library resources as often as those online sources. ${ }^{6}$

In the post test, the nursing, music, and criminal justice classes all indicated that they would use more library resources than they did in the pretest. English was divided in thirds as to the sources they would use but that may have been due to the nature of the questions which involved researching communities so therefore both online and interviews would also be appropriate research tools. ${ }^{7}$

\section{Faculty and student comments}

Based on both student and faculty comments the project was a good beginning. Some comments from faculty include the following: The criminal justice faculty member said, "The content of the papers looked pretty good. I could clearly see who got help from the library and who didn't. Last semester when I asked for an original source roughly one third of the class located one. This time well over half included it."

The music faculty member shared that she felt "that the library lesson was valuable in the sense that almost everyone had a better bibliography by far than I normally see." And the nursing faculty member stated that "the papers were much improved and more effort was clearly put into them." The student comments were encouraging. Some examples were: "I can get the composers biographies from [I]nternet resource or book"; "I would use journal articles or scholarly papers"; "I would use 
the school library now that I know how;" and "You need to know how to search the school databases."

\section{Conclusion}

We learned a great deal from this project. For one thing, students know less than they think they do. They are overconfident about their abilities to find information, and they tend to believe they can find whatever information they need on the Internet.

We were interested to learn that our findings are in keeping with what we read in the literature. In fact, studies done on student perceptions of information literacy reveal that many students who are not information literate are, nevertheless, of the belief that they have the ability to locate and use information. One article concurred that "people who have a lot of confidence about their level of ability are unlikely to seek opportunities to build skills they think they already have."

We also found that those who had received prior information literacy instruction referred to the library resources more often than those who did not, and music and English classes used the most online resources. In the pretest, all students tended to bypass the process of finding, evaluating, and applying information. Rather they answered the question directly thinking they already knew the answer. In the post test, a number of students understood that in the first question we were looking for the type of information and they answered, for example, "a primary source." After the library lesson, at the very least, they picked up the language of doing research.

When we re-structure the project, we will rephrase the questions to be clearer about what we mean by types of information. Also, we need a better assessment tool. Scoring by breadth and depth did give us a general idea, but we hope to find a better way of assessing student answers. Also, using a control group would be another effective way to determine the effectiveness of such a project. Comparing classes that have a library intervention to one which did not would give us a better picture. Ultimately, though, the library lessons helped to improve students' skills and by the way in which many of them answered the scenario questions, it is clear that they are learning how to think critically.

\section{Notes}

1. Cari Merkley, review of "A Mixed Methods Investigation of the Relationship between Critical Thinking and Library Anxiety among Undergraduate Students in their Information Search Process," Evidence Based Library and Information Practice, 4 no. 4 (2009): 63-66.

2. Nahyun Kwon, "A Mixed Methods Investigation of the Relationship between Critical Thinking and Library Anxiety among Undergraduate Students in their Information Search Process," College and Research Libraries, 69, no. 2 (2008): 117-31.

3. Kathleen Dunn, "Assessing Information Literacy Skills in the California State University: A Progress Report," Journal of Academic Librarianship 28, no. 1/2 (2002): 26-35.

4. URLs for the breadth and depth pretest charts: www.formwizards.com/qcc/ slide_10_Image_01.jpg and www.formwizards. com/qcc/slide_10_Image_02.jpg.

5. URLs for the breadth and depth post-test charts: www.formwizards.com/qcc/slide_11 _Image_01.jpg and www.formwizards.com /qcc/slide_11_Image_02.jpg.

6. URLs for the Sources Used in the Pretest for all four subjects: www. formwizards.com/qcc/slide_12_Image_01. jpg, www.formwizards.com/qcc/slide_12 _Image_02.jpg, www.formwizards.com/qcc /slide_12_Image_03.jpg, and www . formwizards.com/qcc/slide_12_Image_04.jpg.

7. These are the URLs for the Sources Used on the Post Test: www.formwizards.com/qcc /slide_13_Image_01.jpg, www.formwizards. com/qcc/slide_13_Image_02.jpg, www . formwizards.com/qcc/slide_13_Image_03. jpg, and www.formwizards.com/qcc/slide_13 _Image_04.jpg.

8. Melissa Gross and Don Latham, "Undergraduate Perceptions of Information Literacy: Defining, Attaining and Self-Assessing Skill," College and Research Libraries 70, no. 4 (2009): 336-50. 